\title{
Turismo de vinho: um catalisador do desenvolvimento rural, através de estratégias de coopetição
}

\author{
Wine tourism: a rural development catalyst driver, through win-win \\ coopetition strategies
}

Josefina Olívia Salvado

Universidade de Aveiro - UA - Aveiro - Distrito de Aveiro - Portugal

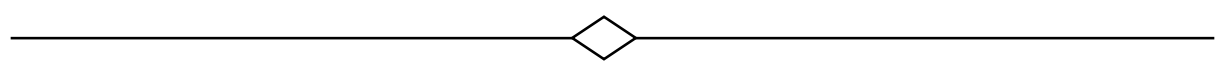

Resumo: As indústrias do vinho e do turismo são "os dois lados da mesma moeda", identificadas como parceiros naturais simbióticos, podendo ser classificados como um ecossistema catalisador do desenvolvimento rural. O turismo do vinho é um excelente veículo de resgate da memória e da construção de uma identidade cultural, garantindo a continuidade das tradições ao longo das gerações, resultante do processo de socialização, onde o indivíduo aprende e interioriza o sistema de valores, de normas e comportamentos de uma determinada cultura. Este tema valoriza as "velhas" atividades rurais e desenvolve outras, investigando oportunidades e fatores de competitividade que existem em cada região. O estudo identifica dinâmicas competitivas que possam moldar o ecossistema do enoturismo usando dados de uma amostra de conveniência de 51 empresas ligadas à indústria do vinho em Portugal. Para alcançar o sucesso empresarial e o desenvolvimento territorial, serão necessárias estratégias de coopetição, criar uma oferta de produtos inovadores e distintivos e promover os produtos endógenos de cada região. Os resultados mostram uma relação complexa entre os stakeholders dentro do ecossistema, com limitadas práticas de cooperação. Foi concluído que, para o enoturismo criar mais-valias sustentáveis nas regiões, é crucial reforçar as parcerias e fortalecer estratégias ganhaganha de coopetição que envolvam todos os stakeholders e ainda garantir uma harmonização da visão e dos objectivos de cada parceiro, alinhados com a especialização inteligente das regiões e focados no crescimento e desenvolvimento sustentáveis dos territórios.

Palavras-chave: Desenvolvimento rural. Turismo de vinho. Coopetição.

\begin{abstract}
The wine and tourism industries are "two sides of the same coin", identified as natural symbiotic partners, classified as a catalytic rural development ecosystem. Wine tourism is an excellent vehicle for the recovery of memory and the construction of a cultural identity, guaranteeing the continuity of traditions throughout the generations, resulting from the process of socialization inherent to it, where the individual learns and internalizes the values and behaviors of a given culture. This theme highlights the "old" rural activities, investigating regional opportunities and competitiveness factors. The study focuses on identifying the competitive dynamics that shape the wine tourism ecosystem, using a convenience sample of 51 Portuguese wine industry companies. In order to achieve business success and territorial development, it will be necessary coopetition strategies and offer innovative and distinctive products from each region. We find evidence of a declining engagement in some interfirm relationships elements. The results showed a complex relationship among stakeholders, where a limited number of wine tourism organizations establish limited cooperation practices with other partners (public and private entities). For an effective integration inside the Enotourism ecosystem all stakeholders (winery business interests and tourism objectives), must build a common vision and mission, adopting win-win coopetitive strategies, which could encourage a responsible attitude/behavior focused on: the sense pride in cultural heritage; commitment to explore the rural landscape's multifunctionalities; and assigning Enotourism innovative experience projects, as a priority.
\end{abstract}

Keywords: Rural development. Wine Tourism. Coopetition. 


\section{Introdução e enquadramento temático}

As indústrias do turismo e do vinho são "os dois lados da mesma moeda", identificadas como parceiros naturais simbióticos (Frase, R., \& Alonso, A., em Carlsan \& Charters, 2006, p.18) e incorporadas num ecossistema, detendo um singular perfil catalisador para o desenvolvimento rural sustentável. O turismo do vinho permite a integração dos setores primário (agricultura), secundário (sector vitivinícola) e terciário (turismo), sublinhando os atributos paisagísticos e mostrando as particularidades do "terroir turístico" regional (Hall e Mitchell, 2002).

O vinho enquanto produto turístico e cultural tornou-se o tema principal do desenvolvimento rural na maior parte das 14 regiões vinícolas de Portugal, evoluindo de modo dissemelhante. Verificam-se grandes desenvolvimentos ao nível do bem-estar social, mas uma evolução negativa no que se diz respeito à demografia e economia (Vieira, 2008). Por outro lado, o turismo tem sido um eixo de intervenção privilegiado pelas políticas e estratégias de desenvolvimento rural, quer pela atenção dada nos planos setoriais quer em termos de financiamento. Ferrão (2000) descreve três tendências centradas na fruição do rural: movimento de renaturalização, centrado na conservação dos valores naturais; procura de autenticidade que conduz à valorização das identidades e memórias genuínas num mundo cada vez mais globalizado; mercantilização das paisagens como resultado do aumento do tempo de lazer e consequente procura de espaços para turismo e recreio.

Neste enquadramento, a secção 1 apresenta uma profunda revisão da literatura sobre os conceitos de turismo de vinho e as suas implicações com a fruição e o desenvolvimento rural sustentável. De notar que Delgado, Cruz, Pedrozo \& Silva, (2008) descrevem o conceito de sustentabilidade integrando as dimensões económica, social, política, cultural, ambiental e territorial. Sepúlveda (2003) argumenta que o desenvolvimento rural deve ter como ponto de partida a análise dinâmica global das áreas: económicas, socioculturais, ambientais e políticoconstitucionais, tendo como principal objetivo fomentar o bem-estar da sociedade rural, potenciando o desenvolvimento sustentável da sociedade. Para ter sucesso no campo do desenvolvimento regional/local, e de acordo com Ribeiro, M. e L. Mergulhão, (2004), o turismo (só por si) não é uma boa base de desenvolvimento regional, devendo possuir algumas especificidades: estar ligado às estruturas sociais que conservam valores, modos de vida e de pensamento de comunidade rural; ser diferenciado de acordo com a singularidade dos recursos endógenos (ambientais, da história e das tradições) do lugar onde acontece; valorizar as "velhas" atividades rurais e desenvolver outras, investigando as oportunidades e os fatores de competitividade que existem em cada região (Cristóvão, 2007); implementar políticas de desenvolvimento dirigidas para a revitalização socioeconómica dos espaços rurais, para que valores como tradições culturais e produtos alimentares de características únicas se preservem e sejam valorizados de forma sustentável (Vieira, 2008); alicerçar o empreendedorismo ao desenvolvimento sustentável e a estratégias de coopetição entre os diversos players regionais. Estes complexos pilares do desenvolvimento do território são explicados na secção 2, através da figura do ecossistema de enoturismo, esclarecendo as sinergias entre a Cultura do Vinho o Território / Paisagem e Turismo. Nos tempos recentes, tem-se assistido à integração do Turismo (setor terciário) com os outros setores (primário e secundário), introduzindo uma união privilegiada no ecossistema do Enoturismo, agregando um vasto conjunto de atividades culturais, experiências turísticas de origem material, imaterial e de sociabilidade ligado à cultura do vinho.

A secção 3 expõe a metodologia e os objetivos do estudo, iniciando com uma proposição de partida. A metodologia assentou num inquérito por questionário on-line, sobre uma amostra de conveniência que estudou 51 viticultores nas 14 regiões vitícolas. A secção 4 revela os resultados do estudo que identificam os principais stakeholders do enoturismo e a extensão das suas parcerias. Os 
resultados mostram uma relação complexa entre os stakeholders dentro do ecossistema, onde um reduzido número de organizações de enoturismo estabelecem limitadas práticas de cooperação com outros parceiros (entidades públicas e privadas). Estes dados finais justificam-se pelo facto da produção de vinho e do turismo se encontrarem em extremos opostos do espectro industrial e as características empresariais de cada actividade diferirem amplamente, não sendo fácil a promoção do estreitamento de relações entre empresas. Hjalager \& Richards (2002) e Carlsen \& Charters (2004) reforçam este argumento quando destacam que 0 pensamento tradicional da gestão associada ao turismo de vinho considera as outras companhias como rivais (competição), não como parceiros potenciais (cooperação), lutando entre si pela liderança no sector e pelo lucro. A secção 5 apresenta os desafios e fatores críticos de sucesso para o Enoturismo em Portugal, apontando algumas linhas geradoras de valor para os negócios e para a sustentabilidade das regiões vitivinícolas. Foi concluído que, para o enoturismo criar mais-valias sustentáveis nas regiões, será crucial fortalecer as parcerias e desenvolver estratégias de coopetição que envolvam todos os stakeholders e ainda garantir uma harmonização da visão e dos objectivos de cada parceiro, alinhados com a especialização inteligente das regiões e focados no crescimento e desenvolvimento sustentáveis dos territórios.

\section{Revisão de literatura - empreendedorismo rural e enoturismo}

O conceito de rural apareceu na Europa no século XIX como o oposto ao urbano, e Ferrão (2000) define quatro aspetos historicamente distintivos do mundo rural face ao urbano: função principal de produção de alimentos; atividade económica dominantemente agrícola; família camponesa como grupo social de referência e tipo de paisagem que reflete o equilíbrio entre os ecossistemas naturais e a atividade humana.
Por outro lado, o rural é geralmente confundido com a agricultura, uma vez que esta é a principal atividade, mas esta confusão deixa cada vez mais de fazer sentido, começando a perceber-se que não existe uma definição exata de rural (Rolo, 2006). A única definição de «zonas rurais» reconhecida internacionalmente (UE, 2006) é da Organização para a Cooperação e Desenvolvimento Económico (OCDE). Em Portugal muitos documentos de referência, publicados pelo Ministério da Agricultura, Desenvolvimento Rural e Pescas (MADRP) adotam esta definição, que assenta na classificação das NUT (Nomenclatura Unidade Territorial) III em "Predominantemente Urbanas" (menos de 15\% da população reside em freguesias com densidade demográfica inferior a 150 hab/km2), "Significativamente Rurais" (onde 15 a 50\% da população residente em freguesias com densidade demográfica inferior a 150 hab/km2) e "Predominantemente Rurais" (onde mais de 50\% da população residente em freguesias com densidade demográfica inferior a 150 hab/km2).

Em Portugal continental as zonas rurais detêm um elevado peso no território, dado que abrangem uma percentagem significativa do território global, vivendo aí mais de um terço da população (Instituto Nacional de Estatística [INE], 2010). A grande maioria das zonas rurais são de baixa densidade vivendo confrontadas com problemas demográficos e socioeconómicos, o envelhecimento, o desemprego, as dificuldades no acesso à educação e à informação, onde a agricultura pode ser a única fonte de rendimento familiar. Sensível a este problema, a União Europeia (UE) tem promovido políticas de desenvolvimento rural, que se centram essencialmente em estímulos ao empreendedorismo, na melhoria da educação e formação, investigação e desenvolvimento e na progressão da inovação e sustentabilidade.

No que respeita ao empreendedorismo rural, Wortman (1990) investigou esta questão e afirmou que o conceito pode ser definido como a criação de uma nova entidade que insere um novo produto num ambiente rural, servindo ou criando aí um novo 
mercado e utilizando uma nova tecnologia. Mackenzie (1992) define empreendedorismo rural como o motor de arranque para impulsionar o desenvolvimento económico, ou seja, o bem-estar económico nas áreas rurais.

O vinho é um dos produtos agrícolas que revelou uma mobilidade e capacidade de expansão mais elevadas ao longo da história, estando presente em todos os continentes. (Carlan, 2012 p. 85). Asero \& Patti (2009) refere o vinho como um " territorial intensive product", uma vez que contém uma forte referência à identidade territorial em que é produzido. Estes novos empreendimentos especialmente associados ao enoturismo, são cada vez mais importantes nas áreas rurais do interior do país, contribuindo para a diversificação da economia local e aumentar o bem-estar da sociedade.

$\mathrm{O}$ vinho como um produto cultural, tem vindo a edificar-se como um ecossistema catalisador do desenvolvimento dos espaço-territórios. De acordo com Brunet (1990), no espaço-território as relações sociais entre os atores locais, fazem surgir um sentimento de pertença à identidade construída, criando laços de solidariedade entre eles. A atividade lúdica associada ao vinho e à vinha não é um fenómeno recente, já os romanos a praticavam por volta de 200 a.C. e de entre as bebidas que os gregos consumiriam, o vinho assumia o primeiro lugar. Alguns romanos abastados possuíam casas de campo onde cultivavam vinhas e produziam pequenas quantidades de vinho para autoconsumo, ou para beber com os amigos nas suas quintas (Johnson's, 1989). A importância social, cultural e religiosa do acto de beber vinho é mais intensa no mundo grego do que no mundo romano (Montanari, 2008, p. 91-92). Esta constituía uma forma de mostrar poder e impressionar os convidados, para além de constituir uma primeira forma de prazer lúdico, associando uma viagem ao campo onde o vinho e a vinha já estão presentes.

O turismo do vinho (ou enoturismo) é um conceito muito complexo que abrange vários campos de pesquisa, interesses dos atores, estratégias territoriais e perspectivas de negócios. A Carta
Europeia do Oenoturismo (2006, p.2) define o turismo do vinho como "o desenvolvimento de todas as actividades turísticas e de tempos livres, dedicadas à descoberta e à valorização cultural da vinha, do vinho e do seu solo". O enoturismo é um importante veículo para um incremento regional sustentável: ao incorporar um conjunto de dinâmicas de identificação, integração e valorização dos recursos endógenos e culturais na oferta turística; ao explorar de forma criativa e inovadora a multifuncionalidade da paisagem rural e ao criar experiências culturais de enoturismo que envolvem todos os stakeholders locais.

Ampliando este conceito, e após consulta de artigos na plataforma cientifica b-on com as palavraschave "Wine Tourism" ou "Enoturismo" e em revistas e livros, encontraram-se diversas perspectivas. Apresentam-se algumas ideias, focando o enoturismo como: produto social e cultural; prática social; estratégia de desenvolvimento do território; motivação dos clientes; promoção do património cultural; experiencia turística diversificada; "terroir turístico"; e elemento de competitividade Empresarial e de Destino.

- Produto Social e Cultural: Hall \& Mitchell (2008) referem o vinho como um produto complexo e enigmático, sendo ao mesmo tempo: um provedor de sustento e um item de luxo; associado a uma vida saudável, enquanto em excesso pode levar à morte; um símbolo de status e bebida de um camponês; Grande significado religioso e cultural, podendo ser associado a comportamento hedonista; um item de moda, experiência e commodity tudo em um.

- Prática social: Brown \& Getz, (2005) argumentam que o turismo do vinho considera o seu consumo como uma prática social, com base no desejo de visitar as regiões vitivinícolas onde os viajantes são induzidos a provar o vinho regional, enquanto viajam por outras razões.

- Estratégia de desenvolvimento do território: Getz \& Brown (2006) argumentam que o turismo de vinho é simultaneamente uma forma de comportamento e uma estratégia utilizados pelos destinos no desenvolvimento da sua oferta 
(promovem e comercializam atrações e imagens relacionadas com o vinho) e uma oportunidade de marketing para as quintas educarem e venderem seus produtos. Getz (2000) afirma que o turismo do vinho tem o potencial de proporcionar uma vantagem competitiva às regiões com uma indústria de uvas e vinhos, bem como gerar negócios para adegas e outros produtos relacionados.

- Motivação dos clientes: Hall (1996) define Enotourism como actividade de visitação de vinhedos, adegas, festivais de vinho e shows de vinho, enquanto os principais fatores motivadores para os visitantes são a degustação de vinhos e / ou experimentar os atributos de uma região vinícola.

- Promoção do património cultural: Cavaco \& Fonseca (2001) acreditam na associação do turismo do vinho com a promoção do património cultural, dando origem a uma nova lógica de desenvolvimento territorial, com impactes multidimensionais (envolvendo processos de mudança geográfica estrutural, construção de produção social significativa, redistribuição mais equilibrada da riqueza, melhoria do rendimento, o aumento das condições de vida e expectativas especialmente dos grupos sociais desfavorecidos).

- Experiência turística diversificada: Williams \& Kelly (2001, p.9) afirmam que "Enoturismo envolve mais do que visitar vinícolas e comprar vinho. É o culminar de uma série de experiências únicas: ambiente, ambiente circundante, cultura e gastronomia regionais, estilos e variedades de vinhos locais ". Charters e Ali-Knight (2002) argumentam que a experiência de enoturismo engloba diversos fatores, como: estilos de vida, educação, ligações à arte, enogastronomia, degustação de vinhos e venda produtos na loja, visita a adegas e quintas, valores económicos, sociais e culturais de um território.

- "Terroir turístico": Hall e Mitchell (2002) usam o termo "terroir turístico" para ilustrar a combinação de elementos físicos, culturais e naturais que dão a cada região o seu apelo distintivo, traçando um paralelo entre as regiões de turismo e as vinhas.

- Competitividade Empresarial e de Destino: Asero e Patti (2009) discutem a ideia de que o vinho assume diferentes significados ao desempenhar um papel predominante, complementar, marginal ou exclusivo na oferta turística de um território, mas em todos os casos é um factor de competitividade para um destino. Eles reforçam essa ideia dizendo que os stakeholders locais devem construir um sistema de relações entre as quintas e as organizações e associações de vinhos para serem bem-sucedidos.

\section{Ecossistema do Turismo do Vinho}

O Turismo de Vinho é um ecossistema complexo e muito fragmentado, com uma complicada interconectividade relacional entre atores, suportado em políticas que visam o desenvolvimento do território rural, a sustentabilidade dos negócios vitivinícolas e de produtos endógenos relacionados e a oferta de autenticidade na experiencia turística. De acordo com Salvado (2016, p.84) o ecossistema do Enoturismo considera três pilares visando 0 a competitividade dos negócios, o desenvolvimento sustentável dos territórios vitivinícolas e a entrega de experiencias turísticas autenticas. A figura seguinte mostra os pilares do enoturismo: Território/Paisagem/Património; Cultura do Vinho e sociabilidade; e Turismo em espaço rural, sustentados por Políticas focadas nos recursos endógenos (figura 1).

\section{Figura 1 - 0 ecossistema de enoturismo}

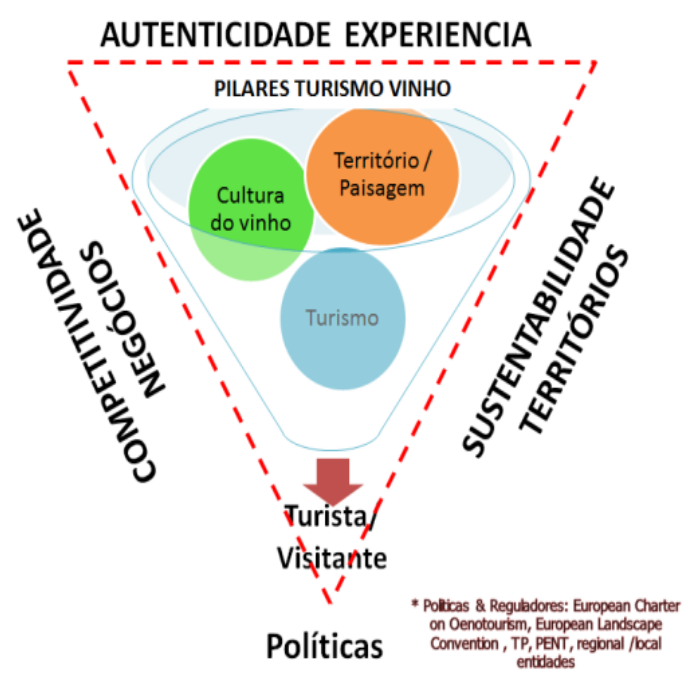

Fonte: Salvado (2016, p.93) com base em Hall, et al., (2000); Deloitte - Vintur Project, (2005); European Charter Wine Tourism (2006). 
Para garantir sucesso do ecossistema apoiamos a proposta de Matos (2013) que sugere a criação de redes de proximidade, através da capacitação dos agentes locais, da formulação de políticas públicas com uma base estratégica forte, devendo ser a base de sustentação da maximização dos serviços e competências existentes e pressupor a criação de novos serviços. Howley \& Westering, (2008), bem como Hall et al (2000) abordam os benefícios da cooperação, somando ao debate as vantagens das redes comerciais, com evidentes benefícios para os territórios das rotas do vinho e para os negócios dos produtores. Ainda segundo Salvado (2016, p.93) detalham-se os diversos pilares do ecossistema de enoturismo:

\subsection{Território/Paisagem/Património}

Território é um conceito relacionado a paisagens, património, governança, planeamento, memórias, legado e sustentabilidade. Território deriva de terra, terra trabalhada e vivida, o que lhe dá desde logo certo estatuto de autenticidade, telúrico, ancorado. Há aqui implícito um sentimento de vivência e de pertença, cheio de simbolismos e de afectividades. O Território é também o resultado de um processo de divisão, histórica e geográfica, estando associado com limites e fronteiras. De acordo com Oliveira Jorge, V. (2005) o espaço-território é entendido como o espaço produzido e apropriado pela sociedade, composto pela inter-relação dos objetos naturais e culturais. O espaço é onde se sedimenta a memória humana, onde é mais densa a teia de significados decifráveis, fruindo uma relação com as pessoas que o habitam. Por outro lado, o espaço geográfico é o contínuo resultado das relações sócio espaciais. Tais relações podem ser económicas (relação sociedade-espaço mediatizada pelo trabalho), políticas (relação sociedade-Estado ou entre Estados-Nação) e simbólico-culturais (relação sociedade-espaço via linguagem e imaginário). A força motriz destas relações é a ação humana e as suas práticas espaciais (Lefébvre, 1991). Dentro deste espaço-território encontramos a Paisagem, que envolve elementos socioculturais resultante da formação histórica, cultural, emocional, físico, e da dinâmica natural. A Convenção Europeia sobre a Paisagem, aprovada pelo Conselho da Europa em Julho de 2000, define a Paisagem como "... uma componente básica do património natural e cultural europeu"; "Uma área percebida por pessoas cujo caráter é o resultado da ação e da interação de fatores naturais e / ou humanos". Dentro desse território geográfico encontra-se o património cultural que, de acordo com Pereiro (2003), tende a ter um significado público, uma comunidade e uma identificação colectiva, sendo uma expressão cultural de um grupo humano que recupera memórias, ritualiza a sociabilidade (identidade de pessoas) e transmite o legado para o futuro. Podemos então considerar que a paisagem é a pegada da sociedade sobre a natureza e paisagens anteriores e torna-se também a consciência social e consciência do território dos autóctones, que devido a estas características se tornam únicos quanto à experiencia turística.

\subsection{A cultura do vinho e sociabilidade}

A vinha e o vinho fazem parte de um património cultural ligado à história e tem sido um elemento essencial para o desenvolvimento económico, social e cultural das diferentes regiões vitívinícolas. A cultura do vinho tem crescido como parte da vida, da cultura, da sociabilidade, de poder e dieta desde tempos imemoriais. Como símbolo cultural, a importância do vinho mudou ao longo do tempo, passando de uma fonte imperativa de nutrição para um complemento cultural para alimentos $\mathrm{e}$ convivência, compatível com um estilo de vida saudável. Promover a Cultura do Vinho significa difundir autenticidade para as origens, e um produto fortemente ligado à gastronomia, aos prazeres do gosto e ao património cultural do território. Segundo Kuper (1999), as diferentes culturas são convenções transmitidas socialmente, dinâmicas e mutáveis, e refletem conjuntos de ideias e valores. De acordo com Brunet (1990), no espaço-território as relações 
sociais entre os atores locais, fazem surgir um sentimento de pertença à identidade construída, criando laços de solidariedade entre eles. Sabourin (2002) corrobora a ideia, de que a valorização conjunta e negociada do potencial das localidades, das coletividades ou das regiões, são chamadas de atributos locais ou de ativos específicos. Jollivet, et all, (2000) considera ainda que uma região tem o poder de se manifestar permanentemente a partir da memória coletiva e das relações sociais que são formadas pelas interações locais e externas.

Mas a presença da cultura local permanece importante na formação da identidade do território, dando-Ihe contornos específicos, sendo um atributo singular quando a integramos no sector do turismo.

De acordo com Deloitte European Enotourism Handbook - Projeto Vintur (2005, p.4) "Sem a cultura do vinho, o Enoturismo não existe. O valor enológicocultural determina o peso do elemento do vinho como um eixo ou uma vértebra da experiência turística". Como referem Santos \& Cunha (2008), a forte associação de produtos locais ao território, como se verifica no caso dos vinhos e das Regiões Demarcadas, servem de referência à qualidade de produtos e ao carácter identitário dos territórios onde são produzidos, pois possuem a capacidade de promover a integração de produtos turísticos diversos em torno de propostas de grande pertinência para o desenvolvimento local sustentável.

\subsection{0 turismo}

O turismo é hoje a mais importante atividade de serviços à escala global com uma forte dimensão cultural. Constata-se que o desejo de viajar, de conhecer novos povos e novas culturas gerou uma interação entre as culturais externas com as culturas locais cujo resultado se diferencia entre os diferentes territórios (podendo gerar aculturação). Isto implica que as políticas devem ser pensadas de forma integrada, levando em consideração as necessidades e potencialidades de cada território (Matos, 2013).

Goeldner \& Ritchie (2006) argumentam que o ecossistema do turismo comporta redes de organizações que se estendem por várias realidades espaciais diferentes, conectando múltiplos tipos de atores relacionando diferentes valores, papéis, interesses, capacidades, práticas e distintos recursos e ideias. De acordo com Williams (2001, p.9) o turismo do vinho é "o culminar de uma série de experiências únicas, como o ambiente, atmosfera, paisagem, cultura e gastronomia regionais, estilos e variedades de vinhos locais". O grande estímulo para os gestores é conceber experiências únicas e inesquecíveis para os visitantes (Cole \& Chancellor, 2009, Saayman \& van der Merwe, 2014). Se o turismo é "experiência", Urry (1999) e Cooper \& Hall (2008) consideram o turismo do vinho como uma "experiência total", por incluir um conjunto de meios endógenos (tangíveis e intangíveis), atracções regionais, equipamentos e infra-estruturas de apoio, actividades de entretenimento, imagens simbólicas locais e valores. Na investigação de Kastenholz [et al.] (2014, p. 15) os contextos de experiências ("experience settings") deverão ser adaptados aos heterogéneos desejos dos clientes/mercados. Kastenholz [et al.] (2014, p. 114) considera que a actividade de Enoturismo tem contribuído para o desenvolvimento e manutenção de actividades económicas tradicionais e beneficiando os produtores locais e regionais.

\subsection{As políticas}

Para garantir o sucesso dos três pilares enunciados, o ecossistema de Enoturismo deve sustentar-se em políticas. Chuck (1997) define Política como um plano geral de alto nível que inclui metas e procedimentos, geralmente encontrados em declarações formais, como leis e documentos e declarações oficiais. Em Portugal esteve em vigor até 2015 o PENT [Plano Nacional de Turismo Estratégico (TP 2013, p.18)] que deu ênfase às indústrias do vinho e do turismo alertando para a necessidade de criar uma diversificada experiência de identidade e experiência regional. É crucial acomodar as políticas nacionais e europeias de Enoturismo com as políticas ligadas ao património, como a Convenção Europeia 
da Paisagem (Decreto n. 4/2005 - Convenção Europeia da Paisagem, feita em Florença em 20 de Outubro de 2000). Para a ELC, todos os stakeholders no território de Enoturismo devem atingir os seguintes objetivos: i) reconhecer as paisagens como componentes essenciais do ambiente das pessoas, expressão da diversidade do seu património cultural e natural e a base da sua identidade; ii) estabelecer procedimentos para a participação do público em geral, das autarquias locais e regionais e de outras partes interessadas na definição e execução das políticas de paisagem; iii) integrar a paisagem nas suas políticas regionais e de urbanismo e nas suas políticas culturais, ambientais, agrícolas, sociais e económicas, bem como em quaisquer outras políticas com possível impacto directo ou indirecto na paisagem. Em Portugal o Governo estabeleceu no seu programa a necessidade de adoptar uma Política Nacional de Turismo (PENT), que vem sendo ajustada à evolução do sector no país, capaz de integrar de forma coerente diversidades e diferenças locais, através de «políticas regionais fortes». Importa que o diagnóstico em turismo considere as políticas e linhas estratégicas definidas pelas organizações internacionais ligadas ao setor, nomeadamente a Organização Mundial do Turismo e a Comissão Europeia (área do turismo), a nível nacional, pela Secretaria de Estado do Turismo e o Turismo de Portugal, a nível regional e local pela Comissão de Coordenação e Desenvolvimento Regional do Norte (CCDR Norte) e as linhas definidas pelas Câmaras Municipais. Portanto, o desenvolvimento dos territórios rurais só é possível se se tiver em conta as especificidades e os atributos únicos de cada região sejam culturais, ambientais, paisagísticas, infraestruturais ou demográficas.

\section{Metodologia}

A proposta de partida declara que as indústrias do turismo e do vinho são "os dois lados da mesma moeda", identificadas como parceiros naturais simbióticos, podendo ser classificados como um ecossistema catalisador do desenvolvimento rural, quando adotam estratégias de coopetição entre stakeholders. O primeiro objetivo visa descrever o complexo ecossistema vitivinícola, composto por 3 pilares, o Território / Paisagem, a Cultura do Vinho, e Turismo, onde as políticas jogam um papel crucial como guia do desenvolvimento regional e o turista como ator principal na experiência turística. $\bigcirc$ segundo objetivo pretende identificar os principais atores no sector do vinho e a dimensão das suas parcerias. No terceiro objetivo serão identificados os fatores críticos de sucesso para o Enoturismo e para o desenvolvimento do território, buscando oferecer autenticidade na experiencia, obter sucesso dos negócios e gerar sustentabilidade territorial.

Para analisar as estratégias de parceria das organizações vitivinícolas e enfatizar alguns elementos críticos do sucesso empresarial, foi realizada uma extensa revisão da literatura (secção 1) que nos permitiu desenvolver uma lista de doze perguntas. Um inquérito por questionário on-line foi projectado, contendo tanto questões estruturadas com espaços em branco a serem preenchidos, como perguntas de múltipla escolha onde a maioria das declarações poderiam ser respondidas usando uma escala de tipo Likert $(1$ = não importante para $5=$ muito importante). Este estudo na perspectiva da oferta foi realizado utilizando também fontes secundárias (estudos do TP, 2014, TP 2015). Uma amostra de conveniência de 51 produtores de vinhos das 14 regiões vinícolas (Vinho Verde, Dão, Távora e Varosa, Porto e Douro, Trás-os-Montes, Bairrada, Beira Interior, Tejo, Lisboa, Alentejo, Península de Setúbal, Algarve, Madeira E Açores) foi a metodologia de recolha de dados primários. As alíneas seguintes servem para mostrar o quadro do enoturismo em Portugal quanto à evolução da produção, o número de atores no sector e a caracterização dos entrevistados.

\subsection{Evolução da produção vitivinícola em Portugal}

De acordo com o IVV (Instituto da Vinha e do Vinho, IP), a evolução da produção de vinho em 
Portugal é apresentada na Figura 2, repartindo-se entre DOP e IGP e atingindo um total de 6009000 hectolitros (2\%) em 2016 (Figura 2), num total mundial de $259000000 \mathrm{hl}$ (Figura3).

Figura 2- Evolução da produção de vinho em Portugal

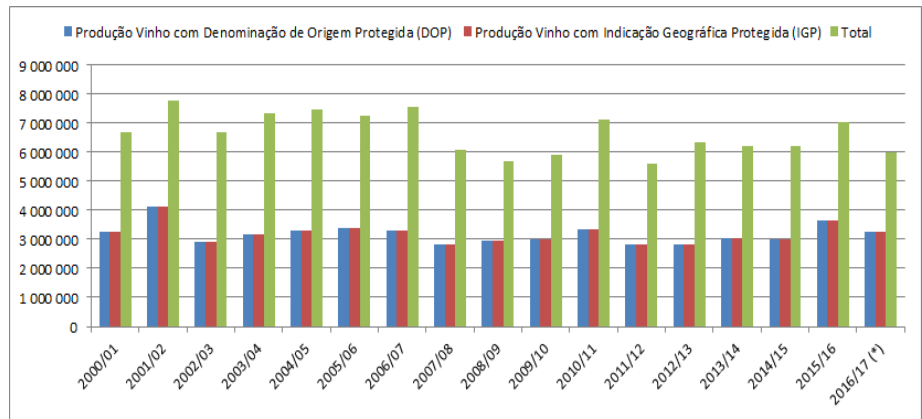

Fonte: produção própria com base em dados de Janeiro 2017 do IVV, IP.

Figura 3- Produção mundial vinho 2016
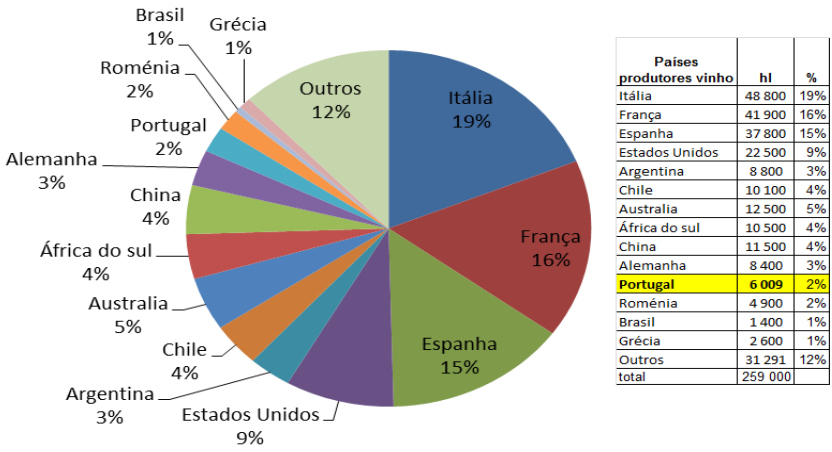

Fonte: produção própria com base em IVV, IP (2016).

A vinha é ainda uma cultura condicionada, pelo que a gestão das superfícies vitícolas plantadas é efectuada por um conjunto de regras definidas nas legislações nacionais ou da União Europeia relativas à questão dos direitos, legitimidade das plantações, variedades e regimes de assistência ao acesso. A área vitícola plantada em Portugal, em 31 de Julho de 2016, era de 190.466,88 hectares ou seja $19 \%$ da superfície de cultivo (Figura 4).
Figura 4 - Total Área de produção - Portugal

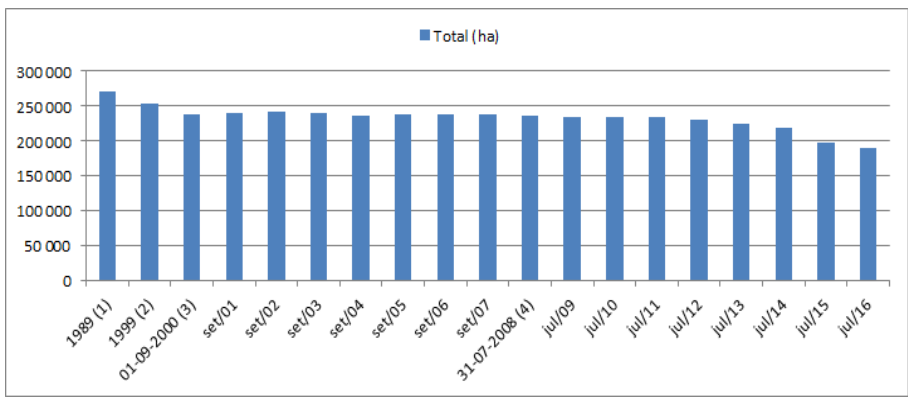

Fonte: Produção própria com base em dados IVV, IP.

Esta actividade envolve 19.988 agentes económicos (Figura 6) cuja "Evolução da Produção Total por Região Vitivinícola (2015 e 2016 em \%)" repartida pelas 14 regiões (Figura 5).

\section{Figura 5 - Evolução percentual da Produção Total} por Região Vitivinícola 2016 vs 2015

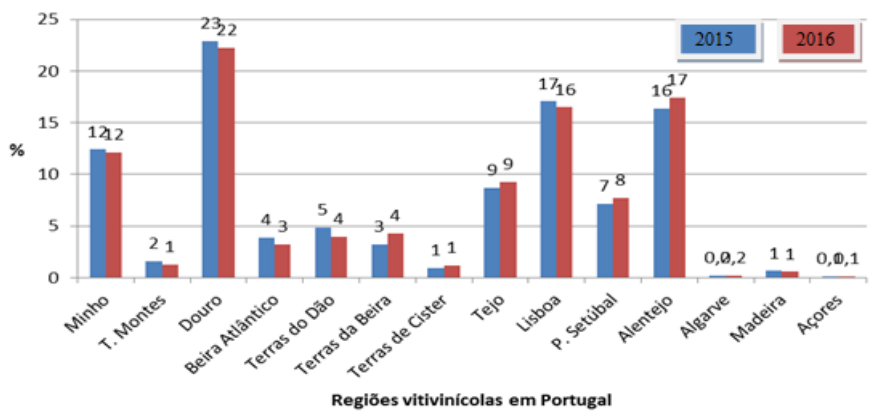

Fonte: Produção própria com base em IVV, IP.

Segundo a TP (2015, p.27), o turismo de vinho é uma actividade muito jovem em Portugal, revelando que $51 \%$ dos empresários iniciaram as suas actividades em 2000 (década) e 27\% iniciaram a sua actividade em 2010-2013. O Enoturismo é também uma actividade complementar à produção de vinho, uma vez que $50 \%$ dos empreendedores são produtores de vinho, 14\% exploram a viticultura e 7\% Turismo no espaço rural. Na perspectiva da Procura, e segundo a TP $(2015$, p.27) 24\% dos turistas têm o Enoturismo como principal motivação de viagem, vivenciando uma experiencia turística diversificada, ao incluir: i) degustação de vinhos; ii) compra de vinho; iii) visita a adegas e vinhas; iv) aprender sobre a paisagem local, comunidades e donos de vinícolas; v) descobrir o património cultural; vi) e compreender a paisagem da região e um expressivo agente 
motivador para o desenvolvimento dos negócios e dos territórios.

Figura 6 - № de Agentes Económicos no Sector Vitivinícola

\begin{tabular}{|l|r|r|}
\hline \multicolumn{1}{|c|}{ Atividades } & Total & $\%$ \\
\hline Armazenista & 3214 & $16 \%$ \\
\hline Destilador & 789 & $4 \%$ \\
\hline Engarrafador & 2852 & $14 \%$ \\
\hline Exportador/Importador & 3002 & $15 \%$ \\
\hline Fabricante de Vinagre de Vinho & 38 & $0 \%$ \\
\hline Negociante sem Estabelecimento & 623 & $3 \%$ \\
\hline Preparador & 449 & $2 \%$ \\
\hline Produtor & 2357 & $12 \%$ \\
\hline Vitivinicultor & 4396 & $22 \%$ \\
\hline Vitivinicultor-Engarrafador & 2268 & $11 \%$ \\
\hline Total & 19988 &
\end{tabular}

Fonte: Produção própria com base em Sivv 15 de Abril de 2016 (http://www.ivv.min-agricultura.pt/np4/360/).

Neste contexto, o estudo começou com 51 organizações (amostra de conveniência), repartidas pelas regiões vitivinícolas identificadas na Figura 7: Alentejo (19,61\%); Porto e Douro (19,61\%); Beira Interior (11,76\%); Bairrada (9,80\%); Dão e Lafões (9,80\%); Lisboa (9,80\%); Vinho Verde (7,84\%); Península de Setúbal (5,88\%); Tejo (3,92\%); Algarve $(1,96 \%)$;

Figura 7- Amostra de 51 empresas de vitivinicultura em \% de respostas por região vitivinícola

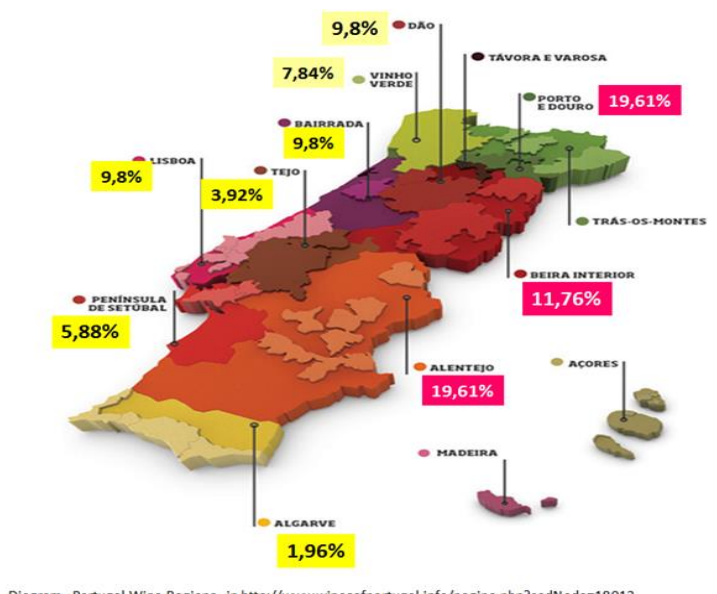

Fonte: produção própria.

\subsection{Caracterização dos entrevistados}

Foi importante entender toda esta amostra, sobre idade, género, posição da empresa, atividade principal e qualificações académicas. Dos entrevistados, $62 \%$ eram do género feminino e $38 \%$ masculino. $\mathrm{Na}$ amostra $32 \%$ dos profissionais de Enoturismo tinha idade entre 41 e 50 anos e $28 \%$ entre 31 e 40. O questionário foi maioritariamente respondido pelos gestores do turismo vitivinícola / vinícola (42\%), seguido por $28 \%$ do CEO / Diretores, $14 \%$ outros cargos da empresa, $10 \%$ técnico, $4 \%$. A actividade principal destaca (Figura 8): engarrafadora (4,35\%); Empresa de Animação Turística (4,82\%); Vitivinícultor (5,80\%); Exportador ou Importador (6,80\%); Produtor (13,59\%); produtor-engarrafador (26,08\%); Turismo Rural (37,39\%).

\section{Figura 8 - Atividade principal}

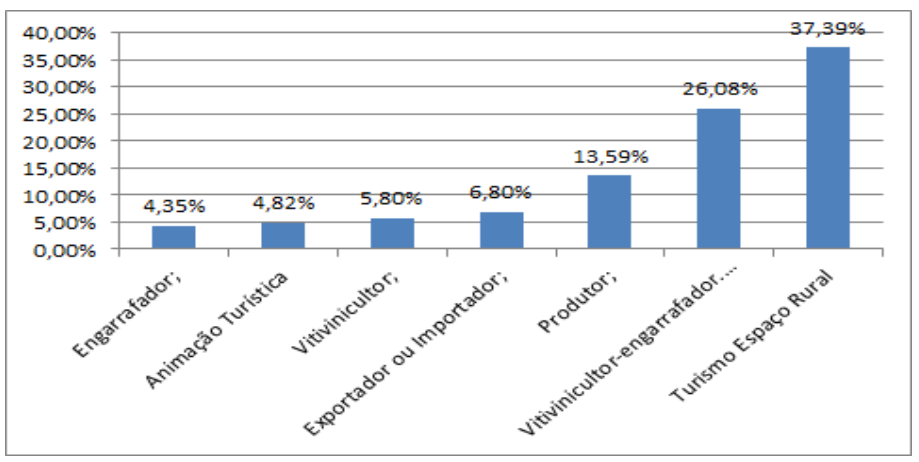

Fonte: produção própria.

O turismo é uma indústria intensiva em mão de obra, envolvendo mais do que visitar vinícolas e comprar vinho, exigindo vários talentos e competências relacionados com a paisagem, o património e a identidade de cada território. Assim, é importante conhecer o tamanho da empresa, a composição e competências dos recursos humanos tendo $56,86 \%$ uma licenciatura e $25,49 \%$ um grau de mestrado. Os dados revelaram que $41,18 \%$ das empresas tinham até 5 funcionários, sendo 0 enoturismo uma actividade secundária para o sector vitivinícola. 


\section{Resultados - Enoturismo e relações de cooperação}

Em Portugal, o turismo do vinho é um produto que usa intensivamente o território, sendo parte de um ecossistema de negócios, porque engloba uma variedade de indústrias, combina os interesses dos diferentes stakeholders. Segundo o TP (Turismo de Portugal, 2014), no estudo do "Enoturismo em Portugal", a contribuição do turismo do vinho para a indústria vitivinícola é considerada positiva $(62 \%$ consideram a contribuição do turismo do vinho como muito importante ou importante).

Assim, a indústria do vinho e o turismo são "dois lados da mesma moeda". São dois setores poderosos para o desenvolvimento rural, exigindo estratégias de coopetição entre stakeholders, como mencionado por Inácio (2008, p.132) e Getz (1997). Segundo o TP (2015, p.27), o turismo do vinho é uma actividade muito recente: $51 \%$ das empresas começaram na primeira década do século XX e 27\% iniciaram a actividade entre 2010 e 2013, e em 50\% dos casos a actividade principal é Vinho, 14\% exploram a viticultura e $7 \%$ o turismo nas zonas rurais. O Turismo de Portugal (2014) considera o turismo do vinho, como um dos dez produtos estratégicos para o desenvolvimento do turismo em Portugal.

O desenvolvimento das empresas vitivinícolas deu origem a novas oportunidades e desafios que exigem uma redefinição de estratégias setoriais e regionais, bem como a definição de objectivos com foco nos recursos endógenos de cada território, para expandir o ecossistema e proporcionar uma experiência turística diferenciadora.

De acordo com a TP (2015), Portugal representa na Europa cerca de $2,5 \%$ do total das receitas turísticas internacionais, com vários elementos diferenciadores, tais como: clima e luz; história, cultura e tradição; hospitalidade e diversidade concentrada, autenticidade, segurança e qualidade competitiva. A análise SWOT (coloca a tónica nos pontos fortes, fracos oportunidades e desafios) revela a cultura do vinho e da vinha como um tema importante num ambiente turístico multifacetado e Portugal como destino de excelência e autenticidade histórico-cultural.

\subsection{Enoturismo e relações de cooperação}

O estudo revela a importância dada à cooperação e às relações entre parceiros de negócio, sendo valorizados com diferentes intensidades (Figura 9). As empresas de enoturismo devem perceber a importância de desenvolver relações de coopetição ganha-ganha entre todos os stakeholders e obter benefícios dessas sinergias. De acordo com TP (2014, p. 11), os níveis de parceria em Enoturismo são muito baixos: cerca de $57 \%$ das empresas relataram ter parcerias com outros players, tais como: empresas de turismo recreativo (30\%); Agências de viagens (29\%); Alojamento (14\%); Alimentos e bebidas $(12 \%)$ e entidades institucionais $(9 \%)$. De notar que o grau de colaboração com entidades institucionais, mostrou que (52\%) integram rotas de vinhos, (49\%) pertencem a Comissões Regionais Vinícolas e (45\%) representantes municipais.

Figura 9- Enoturismo: Relacionamento, importância e valorização (\%)



A Figura 9 compara os diferentes níveis de relacionamento entre stakeholders quanto a relacionamento (\%) e a importância comercial atribuída a essa parceria (\%). O nível de valorização de relacionamento (\% valorização) é a diferença entre níveis de relacionamento (\%) e a importância (\%). É 
claro que, apenas os parceiros ligados a alimentos e bebidas, empresas de turismo e marketing e promoção têm uma importância similar quando comparada com o nível de parceria. Todos os outros elementos têm um indicador de valorização mais baixo, o que significa uma rede de cooperação entre parceiros muito suave.

Para uma integração efetiva dentro do ecossistema de enoturismo, todas as partes interessadas (interesses de empresas vinícolas e objetivos de turismo) devem construir uma visão e missão comuns, adotando estratégias coopetitivas vantajosas para o futuro, o que poderia encorajar uma atitude / comportamento responsável focado em: património; reconhecimento o enoturismo como um veículo importante para o desenvolvimento regional; compromisso de explorar a multifuncionalidade da paisagem rural; e a atribuição de projectos de experiência inovadora em Enoturismo, como uma prioridade.

\section{Enoturismo e estratégias de coopetição: desafios}

As relações entre stakeholders devem ser ancoradas em redes co-opetitivas, aproveitando as habilidades e as sinergias dos parceiros (Dodd, 1995; Hall et al., 1997; Getz et al., 1999; Beverland et al., 1998). As estratégias de coopetição, nas quais as empresas cooperam e competem simultaneamente (Nalebuff e Brandenburger, 1996), aceitam relações mais complexas entre vários parceiros (Dagnino e Padula, 2002). De acordo com Gnyawali et al. (2008), as estratégias de coopetição poderiam levar as empresas a se concentrarem sucessivamente na concorrência e, em seguida, na cooperação.

De acordo com Zineldin (2004), a coopetição é definida como uma situação de negócios em que as partes independentes cooperam e coordenam suas atividades, ajudando assim a atingir metas mútuas, mas ao mesmo tempo competem entre si e com outras empresas.

É crucial definir um diálogo aberto e sincero entre profissionais de desenvolvimento e comunidades locais, como parceiros num processo de descoberta aberto. O resultado final incentivará um comportamento responsável entre todos os stakeholders, definindo projectos prioritários para 0 desenvolvimento do turismo e a salvaguarda do património; garantindo uma abordagem equilibrada entre a conservação do território e a promoção do local; e identificando oportunidades estratégicas para crescimento económico e criação de emprego.

\section{Conclusion}

Transformar uma região vitivinícola num importante destino turístico exige lógica de concentração, sinergia, redes coopetitivas e diversidade de oferta, em combinação com um vinho de qualidade e alguma notoriedade do produto, sem esquecer a identidade e o património desses territórios. Trata-se basicamente de uma relação ganha-ganha, aproveitando as sinergias dos stakeholders, sendo mutuamente benéficas.

Os objetivos de harmonização são claros: cooperação em torno de objetivos comuns, reforço das redes, respeito pela identidade cultural e autenticidade e melhoria da multifuncionalidade paisagística nas zonas rurais; identificar e trabalhar segmentos de mercado interessados na experiência de enoturismo; encorajar as empresas de turismo vinícola a especializar-se, desenvolvendo programas de experiência única; investir em qualificações, infraestruturas e serviços para atingir níveis de excelência em hospitalidade; estabelecer padrões de qualidade em experiências de turismo de vinho; desenvolver e comunicar conteúdos que reforcem a identidade territorial; incentivar o aumento de eventos e rotas de turismo de vinho; complementar o mercado vitivinícola com outros recursos regionais endógenos; reorganizar Rotas do Vinho de acordo com os princípios da Carta Europeia de enoturismo; fortalecer as redes; e estender os benefícios para as comunidades locais. 


\section{Referencias}

Asero, Vincenzo \& Patti, Sebastiano. From Wine Production to Wine Tourism Experience: the Case of Italy. American Association of Wine Economists, 2009. in http://www.wineeconomics.org/workingpapers/AAWE_WP52. pdf, access in 13-01-2015.

Ballart, Josep. El Património Histórico y Arqueológico: Valor Y Uso. Barcelona: Editorial Ariel Patrimonio Historico, 1997.

Beverland, M.; James, K.; James, M., Porter, C. \& Stace, G. Wine tourism: missed opportunities in West Auckland, Australian and New Zealand. Wine Industry Journal, 13, 407, 1998.

Brandenburger, Adam M. and Nalebuff, Barry J. CoOpetition: A Revolution Mindset that Combines Competition and Cooperation. Crown Business. (1996) ISBN 9780385479509

Brown, G. P. \& Getz, D. Linking wine preferences to the choice of wine tourism destinations. Journal of Travel Research, 43, 266-276. (2005).

Brunet, R. Le territoire dans les turbulences. Paris: Reclus, p.224, 1990.

Carlan, C.. Vinho: Comércio e Poder no Mundo Antigo, in Candido, Maria Regina (Org.), p. 85, 2012.

Carlsen \& Charters. Global Wine Tourism: research, management \& marketing.2006

Carlsen, J. \& Carters, S. (Org.) Wine Tourism. (Special Issue), Journal of Wine Research (15, 1). Oxford: Carfax Publishing. 2004.
Cavaco, C., \& Fonseca, L. Território e Turismo no Brasil: uma introdução. Lisboa: CEG. 2001.

Charters, S., and Ali-Knight, J. Who is the wine tourist?. Tourism Management, 23 (3), pp. 311-319. 2002.

Chuck, Y. International Tourism: a Global Perspective. World Tourism Organization (WTO) Publications, Madrid. 1997.

Cole, S. T., \& Chancellor, H.C. Examining the festival attributes that impact visitor experience, satisfaction and re-visit intention. Journal of Vacation Marketing, 15, 323-333. 2009.

Cooper, C., \& Hall, C., M. Contemporary Tourism. Routledge Taylor \& Francis Group. 2008.

Cristóvão, A. As Transformações do Espaço Rural e as Dinâmicas de Desenvolvimento. O Turismo no Espaço Rural e a Multifuncionalidade da Paisagem. Évora. 2007.

Dagnino, Giovanni \& Padula, Giovanna, Coopetition Strategy: A New Kind of Interfirm, 2002.

Delgado, N., Cruz, L., Pedrozo, E. \& Silva, T. Empreendedorismo orientado a sustentabilidade: as inovações do caso Volkmann. Cadernos EBAPE, 6(3). 2008.

Dynamics for Value Creation. In : https://www.researchgate.net/publication/228 605296.

Deloitte Vintur Project European Enotourism HANDBOOK. Project: "VINTUR", 2005.

Dodd, T. Opportunities and pitfalls of tourism in a developing wine industry. International Journal of Wine Marketing, 7(1), 5-16. 1995. 
Dyer, J. Collaborative Advantage: Winning through Extended Enterprise Supplier. Oxford University Press Networks, 2000.

European Charter on Oenotourism (2006) in http://www.recevin.net/userfiles/file/VINTUR /Charte_EN.pdf, accessed in 2-10-2015.

European Landscape Convention. Foreign and Commonwealth Office, King Charles Street, London, SW1A 2AH. , 2000. http://www.official-documents.gov.uk/.

Ferrão, J. Relações entre mundo rural e mundo urbano: evolução histórica, situação actual e pistas para o futuro. EURE (Santiago) Vol.26, n. .782000 .

Gastal, Marcelo L. A representação social do desenvolvimento rural sustentável construída por assentado: o caso do projeto Una. Tese de doutoramento, Universidade de Brasília, Brasil. 2008.

Getz, D. \& Brown, G. Benchmarking wine tourism development: the case of the Okanagan Valley, British Columbia, Canada. International Journal of Wine Marketing $(18,2)$, Emerald. 2006.

Getz, D. Event Management and Event Tourism. New York: Cognizant Communications Corporation 1997.

Getz, D. Explore Wine Tourism: management, development \& destinations. Cognizant Communication Corp. 2000.

Getz, D.; Dowling, R.; Carlsen, J., \& Anderson, D. Critical success factors for wine tourism. International Journal of Wine Marketing, 11(3), 20-43. 1999.
Gnyawali D. R.; He J., \& Madhavan, R. Co-opetition: Promises and Challenges. C Wankel (Ed), 21st Century Management. Thousand Oaks, CA, pp.386-398. 2008.

Goeldner, R. and Ritchie, B. Tourism: Principles, Practices, Philosophies. Hoboken (NJ), John Wiley \& Sons, (10th ed.). 2006

Hall, C. Tourism - Rethinking the Social Science of Mobility. Essex: Prentice Hall. 2005.

Hall, C. ; Johnson, G.; Cambourne, B.; Macionis, N.; Mitchell, R.; \& Sharples, L. Wine tourism: an introduction in Wine Tourism Around the World -Development, management and markets. Butterworth-Heinemann. Oxford. 2000.

Hall, C. M.; Cambourne, B.; Macionis, N. and Johnson, G. Wine tourism and network development in Australia and New Zealand: review, establishment and prospects. International Journal of Wine Marketing, 9(2/3, 5-31). 1997.

Hall, C. Michael, et al. (eds.). Wine Tourism around the World - Development, management and markets. Oxford: Butterworth-Heinemann. 2002.

Hall, C., and Mitchell, R. Wine Marketing: A Practical Guide. Elsevier. 2008.

Hall. C. Wine Tourism in New Zeland. In J. Higham (Ed.). Proceedings of Tourism Down Under II. Research Conference (pp.109-119). Dunedin: University of Otago. 1996.

Hjalager, A. \& Richards, G., (Eds.). Tourism and Gastronomy. Oxon: Routledge. 2002.

Howley, M. \& Westering, J. Developing wine tourism: A case study of the attitude of English wine 
producers to wine tourism . Journal of Vacation Marketing, vol. 14, no. 1, pp. 87-95. 2008.

Inácio, A. O Enoturismo em Portugal: da "Cultura " do vinho ao vinho como cultura. Universidade de Lisboa, Faculdade de Letras. Departamento Geografia. Tese doutoramento. 2008.

INE. Anuário Estatístico de Portugal 2010.

INE- Instituto Nacional Estatistica, Estatísticas Agrícolas - Statistics Portugal 2013. ISBN 978-989-25-0265-6. 2014.

IVV-Instituto da Vinha e do Vinho, I.P. Evolução da Área Total de Vinha - Portugal Continental Série 1989 a 2015. in http://www.ivv.minagricultura.pt/np4/35. 2014. (accessed in 210-2015)

Johnson, P. História dos Judeus. Rio de Janeiro, Imago. 1989.

Jollivet, M. \& Pavé, A. O meio ambiente: questões e perspectivas para a pesquisa. In: Vieira, P.F. \& Weber, J. (orgs) Gestão de recursos naturais renováveis e desenvolvimento. Novos desafios para a pesquisa ambiental. São Paulo: Cortez, p. 115-146. 2000.

Kuper, A. Culture: the anthropologist's account. Cambridge: Harvard University Press. 1999.

Lefebvre, Henri. Espacio y Política. Barcelona: Peninsula. 1976.

Montanari, M. Sistemas Alimentares e Modelos de Civilização, in Flandrin, J. (coord.) e Montanari, M., História da Alimentação - Dos primórdios à Idade Média. $2^{\underline{a}}$ ed., Lisboa, Terramar, pp. 91-101. 2008.
Matos, M., Governança e Políticas Públicas em Territórios de Baixa Densidade. Dissertação de Mestrado. Lisboa: ISCTE-IUL. 2013. Acessível em https://repositorio.iscte-iul.pt/bitstream/10071/7357/1/Dissertacao\%2 0Concei\%C3\%A7aoMatos\%20\%20Governan\%C3\%A7a\%20e\%20PP\%20e m\%20TBD\%20-\%20Sem\%20CV.pdf.

MacKenzie, Lynn Ryan. Fostering entrepreneurship as a rural economic development strategy. Economic Development Review, 10(4), 3844. 1992

Moore, J. Predators and prey: a new ecology of competition. Harvard Business Review, MayJune, 75-86. 1993

Moore, J. Death of Competition: Leadership and strategy in the age of business ecosystems. Harper Business. ISBN: 0887308503. Reprint edition. 1997.

Moore, J. Business ecosystems and the view from the firm. Antitrust Bulletin: Spring 2006; 51, 1; ABI/INFORM Global, pg. 31. 2006.

MORENO, L. A Serra do Açor e o Piódão: Refúgios de uma ruralidade recriada. in Cavaco (1999), Desenvolvimento Rural: Desafio e Utopia, Centro Estudos Geográficos, Universidade de Lisboa. 1999.

Oliveira Jorge, V. Espaço, meio, paisagem, território, região e lugar na experiência de um arqueólogo: alguns contributos reflexivos. Trabalhos de Antropologia e Etnologia. 45, 159-172. 2005.

Pereiro, P., X. Patrimonialização e transformação das identidades culturais. In Portela, J. \& Castro Caldas, J. (coords.). Portugal Chão. Oeiras: Celta editora, pp. 231-247. 2003. 
Ribeiro, M. e Mergulhão, L. Turismo e desenvolvimento das regiões do interior. A perspectiva dos autarcas. In IV Congresso Português de Sociologia, Lisboa, 25 - 28 Jun. 2004.

Sabourin E. In Sabourin Eric (ed.), Teixeira Olivio Alberto (ed.). Planejamento e desenvolvimento dos territorios rurais : Conceitos, controvérsias e experiências. Petrolina: EMBRAPA, p. 21-37. 2002.

Santos, N., e Cunha, L. Novas oportunidades para o espaço rural. Análise exploratória no Centro de Portugal. In N. Santos e A. Gama. Lazer. Da libertação do tempo à conquista das práticas. Coimbra: Imprensa da Universidade, pp. 209-225. 2008.

Schmit, J. Sociedade, natureza e desenvolvimento sustentável: uma abordagem preliminar. Porto Alegre: PPGS/UFRGS. 1995.

Rolo, J. Rendimentos: terra e valores acrescentados das actividades agro-rurais - quantificações e dinâmicas espaciais. Programa de Investigação e de Formação pós - graduada, INIAP, Lisboa, Portugal. 2006.

TP-Turismo de Portugal. Enoturismo em Portugal. 2014. In http://www.turismodeportugal.pt/Portugu\%C3 $\%$ AAs/ProTurismo/competitividadeeinovacao/ setoresdeatividade/Documents/Carateriza\%C 3\%A7\%C3\%A30\%20das\%20Unidades\%20d e\%20Enoturismo.pdf

TP-Turismo de Portugal. Plano Estratégico para o Turismo. Lisgráfica, Impressão e Artes Gráficas, S.A.Lisboa. 2013.

TP-Turismo de Portugal. Plano Estratégico para o Turismo. Lisgráfica, Impressão e Artes Gráficas, S.A.Lisboa. 2020.
Urry, J. O Olhar do Turista: Lazer e Viagens nas Sociedades Contemporâneas. 2ª ${ }^{a}$. Ed. Studio Nobel/SESC: São Paulo. 1999.

Vieira, C. Desenvolvimento ao "sabor" do Turismo? O caso da Serra da Estrela. Tese de Mestrado em Gestão e Planeamento em Turismo, Universidade de Aveiro, Portugal. 2008.

Williams, W. \& Kelly, J. Cultural Wine Tourists: Product Development Considerations for British Columbia's Resident Wine Tourism Market. International Journal of Wine Marketing (13,3). U.K.: Emerald; 59-76. 2001.

Wortman. M.S. Rural Entrepreneurship Research: An Integration Into the Entrepreneurship. Agribusiness, 6(4), 329-344. 1990.

Zineldin, M. Co-opetition:The organisation of the future. Marketing Intelligence \& Planning, 22(6/7), 780-789. 2004.

Zook C., \& Allen, J. Profit from the Core. Published by: Harvard Business School Press. 2001. In http://vedpuriswar.org/Book_Review/Business Strategy/Profit\%20from \%20the\%20Core.pdf. 